$\xi=-1$

\title{
Investigation of Mechanical Properties of E-Waste Polymer Blend
}

\author{
${ }^{1}$ Sanjay Sharma, ${ }^{2}$ G Santhosh, ${ }^{3} \mathrm{~K}$ G Pradeepa \\ ${ }^{I}$ Department of Mechanical Engineering, NMAM Institute of Technology, Nitte, 574110, India \\ ${ }^{2}$ Department of Mechanical Engineering, NMAM Institute of Technology, Nitte, 574110, India \\ ${ }^{3}$ Department of Polymer science and technology, SJCE Mysore, Karnataka, India \\ *Corresponding author E-mail: ${ }^{1}$ sanjaykatpady@gmail.com
}

\begin{abstract}
E-waste collection has turned into a noteworthy worry for the greater part of the natural issues. The E-waste aggregation turns into a quick natural issue which can build up the human wellbeing risks, for example aggravation and oxidative pressure forerunner to cardiovascular illnesses, malignancy, skin ailments, and DNA harm and so forth. Supplanting the E-waste into the valuable items is the major testing process. In this study WEEE plastics and pure polypropylene is blended in different composition and investigation of its tensile flexural and impact properties is done in order to improve mechanical properties by optimizing the right composition which have larger volume than that of E-waste.
\end{abstract}

Keywords: E-waste, Polypropylene, Acrylonitrile-butadiene-styrene, Polymer blend, Recycling

\section{Introduction}

Advancement of technological and extreme marketing of electrical and electronic equipment (EEE) throughout the world has increased the availability of electrical gadgets. Usefulness of EEE majorly depends on its life cycle or arrival of newer version superior than the exiting one. Once EEE reaches their end of life or managed with the advanced version the disposed items are termed as "Waste Electrical and Electronic Equipment".

Waste Electrical and Electronic Equipment (WEEE) is otherwise called E-waste which is acquired from disposed of electrical and electronic parts or gadgets, for example, PCs, cell phones, cooler, conservative circle, printed circuit sheets and so forth. WEEE is getting to be one of the quickest developing waste streams around the world. E-squander is a rising worldwide worry because of its alarmingly expanding volume and poisonous quality. Yet, the size of WEEE development has not been related to their gathering, reusing, renovating and reuse. Therefore, the life-cycle of WEEE is a straight movement with assembling, utilize, stockpiling and waste transfer. By and by crude reusing practices of casual area for the most part force a genuine risk to the earth and human wellbeing because of the extreme poisons discharge into air, soil and ground water. In numerous creating nations, especially lowwage and center wage nations, a noteworthy extent of e-waste parts is discarded in unsanitary landfill destinations. Similarly, informal e-waste recycling is widely practiced. Wires are burned in open spaces to remove plastic and recover copper. Acid extraction is also practiced retrieving precious metals like gold, platinum, palladium, and silver from Printed Circuit Boards (PCBs). Such practices can be found in countries such as China, India, Pakistan, Vietnam, the Philippines, Nigeria, and Ghana, where e-waste is disassembled using rudimentary methods to recover valuable metals by people who lack the facilities to safeguard the environment and public health. The two pertinent Directives on WEEE and Restriction of Hazardous Substances (RoHS) at first began amid their preliminary stage as single Directive, going for the diminishing the ecological effect of WEEE all inclusive. At present India is also fastest e-waste accumulating country in the world. Government of India taken lot of measures to overcome the accumulation of WEEE by locating several e-waste collection centers at each district of every state.[13]

According to Plastics Europe, mechanically recycled plastics coming from EEE represent less than $2 \%$ of the total amount of mechanical recycling of plastics the origin of this material is mainly large domestic appliances (e.g. refrigerators). The inner liner of refrigerators is an example of an appliance with an increasing recycling rate. [4].

Plastics in WEEE plastics are made of crude materials including oil, petroleum gas, carbon, basic salt and different items. At show, plastics are about totally gotten from petrochemicals created from fossil oil, of which around $4 \%$ is utilized for plastic generation at the worldwide level. From the substance see point, plastics are manufactured materials with large scale sub-atomic structures, which can be recouped by the crude materials from which the plastics are initially made. It is assessed that the worldwide creation of plastics roughly expanded to about 600Mt from 2013 to 2017 , and China remains the main plastics maker with $24.8 \%$ of the world's aggregate generation took after by Europe representing $20 \%$. Plastics, taking up around $20 \%$ of the aggregate WEEE, incorporate 5\% fire hindered plastics and $15 \%$ non-fire impeded plastics, as appeared in figure 1 . WEEE can be founded on 15 unique sorts of designing plastics, including acrylonitrilebutadiene-styrene (ABS),high affect polystyrene (HIPS), polyethylene (PE), polypropylene (PP), polystyrene (PS), styreneacrylonitrile (SAN), polyesters, polyurethane (PU), polyamide (PA), mixes of polycarbonate(PC)/ABS and mixes of HIPS/poly (p-phenyleneoxide)(PPO). 
As per an immediate investigation of describing the plastic constituents of WEEE, roughly 3400 things, including cooling machines, little WEEE, CPUs, replicating hardware, printers, CRT screens and CRT TVs were portrayed with the examination finding around $6000 \mathrm{~kg}$ of plastics with a few polymer composes. As a rule, the predominant polymers were observed to be PS, ABS PC/ABS, HIPS and PP, comes about that the mix of HIPS and ABS can represent around 55\% of all WEEE plastics. Alongside this noteworthy assortment of materials, the various added substances (both natural and inorganic) are likewise added to plastics, for example, metals and Brominated Flame Retardants (BFRs), which would influence squander administration techniques because of their potential dangers. The gadgets business represents the best utilization of BFRs, more than in autos or furniture. In PCs, BFRs are utilized fundamentally in the pcbs, connectors, plastic covers, and links. BFRs are additionally frequently utilized as a part of plastic fronts of TVs and household kitchen apparatuses. figure 2 beneath demonstrates the Plastic sythesis exhibit in squander electrical and electronic gear (WEEE) [5-7].

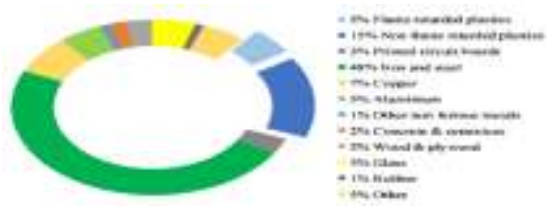

Fig 1: Average composition of WEEE [1]

The reusing rate of such waste plastics is still very low as it here and there costs more to reuse than the estimation of the reused material/item itself. Because of its dangerous nature, arrive filling or dumping of e-squander is exceptionally bothersome. New methodologies are required to reuse and recoup material assets from the consistently developing heaps of electronic waste and for their use in an assortment of uses.[8]

Polypropylene has been very successfully applied to the forming of fibers due to its good specific strength and it is the lightest plastic available with a density of $0.905 \mathrm{~g} / \mathrm{cm}^{2}$ and have good strength, stiffness and higher temperature capability .[9]

Formation of good Polymer blend compatibility is the major point needed to be considered, if the polymer retains their domains then those polymer are incompatible. The compatibility can also be increased or improved by the addition of tertiary polymer or by the addition of compatibilizer as bridging material between the two phases.[10]

Polystyrene is mixed with either polypropylene or High density polyethylene to yielded uniform tensile strength. ABS being the major content with small amount of HIPS, present in the plastics of computer outer panel and keyboard. Polypropylene might be the good polymer to blend.[11]

Glass transition temperature of the blend found to increase as the addition of grafted co-polymer with the blend which justifies that blending compatibility between the ABS/PP. One of the case study shows that by the addition of compatibilizer PP grafted with HEMA will induce beta phase in the composite which binds the composite with more compact. [12-13].

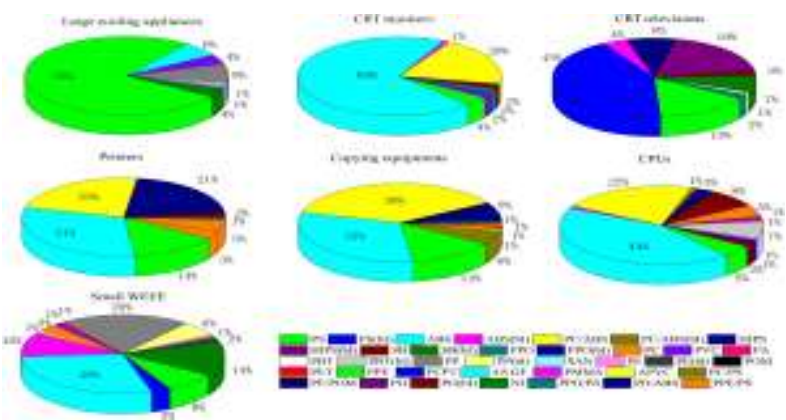

Fig 2: plastic composition of WEEE [2]
From the past work it can be observed that PP composite is added with polymeric waste of Printed Circuit Boards (PCBs) as one set and other set as addition of small amount of rubbery content into the composite. The major inference was tensile strength and tensile modulus of the composite both the set was decreasing but when compared to composite without rubbery content tensile strength of the composites with rubbery content was more since the nucleation of beta phase was observed in PP.[14]

In another case study done on polymers present in printers. 20 printers where used for the study each of them where dismantled and separated with metal, non metal and polymeric parts. The major polymer present in the printers where HIPS $90 \%$, PS $10 \%$, ABS $10 \%$. these combination was blended to find their mechanical properties. Composition with HIPS/ABS was found to be high value of tensile strength with $39 \mathrm{MPa}$ when compared to HIPS/PS with $37 \mathrm{MPa}$.[15]

In this study an investigation has been done on mechanical properties of the e-waste ABS and PP blend in their individual state.

\section{Experimental}

\subsection{Materials}

Waste electrical and electronic equipment (WEEE) or E-waste, specifically computer housing and keyboards donated by Prime Ewaste Recyclers, Bangalore and Shobith Industries, Mysore respectively. Up to $5 \mathrm{kgs}$ of discarded computer housing and $8 \mathrm{kgs}$ of dismantled keyboard has been collected. The collected dismantled E-waste are shown in the fig 3 below. Pure polymer Polypropylene (PP) is the blending material used in the study supplied to the SJCE College from the company named HPCL Mittal energy limited Punjab.
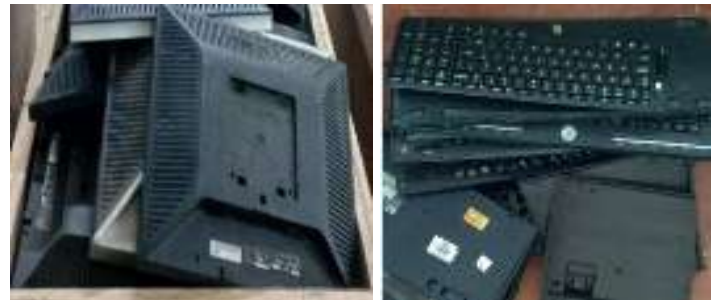

Fig 3: Dismantaled computer outer housing and dismantaled keyboards

\subsection{Methods}

Firstly obtained dismantled computer housing panels and keyboard where crushed into granules using Granulator and dried for 24 hours at $60^{\circ} \mathrm{C}$ in an Hot air Oven along with the pure Polypropylene. fig 4 below shows the granulator used for crushing the E-waste and collected as granules.

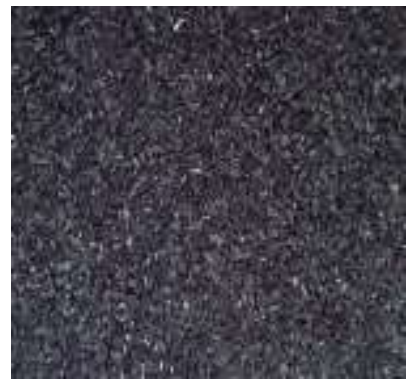

Fig 4: Granulated e-waste

Second step is to melt mixing the e-waste granules with pure PP using an Rheomix extruder. Different composition has been considered starting from 100\% E-waste, 90/10, 80/20, 70/30, $60 / 40$ continuing till $100 \%$ PP. Here $90 / 10$ indicating $90 \%$ of E- 
waste and $10 \%$ of PP. The melting temperature of PP is $1900 \mathrm{C}$ and that of E-waste material (ABS) is 2100C. Hence the temperature maintained between $1900 \mathrm{C}$ to $2150 \mathrm{C}$ with a rotation speed of $120 \mathrm{rpm}$ in order to get uniform blend. fig 5 below shows the extrusion process carried out during course of work.

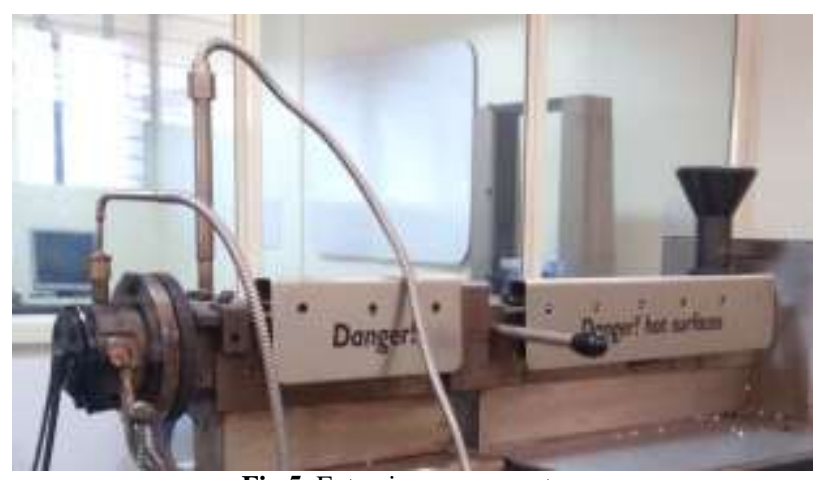

Fig 5: Extrusion process setup

Next step is to palletize the uniformly extruded differen composition of E-waste and PP in an Palletizer, Those pellets dried for 24 hours at $600 \mathrm{C}$. fig 6 below shows the pelletized polymer blend of one of the composition.

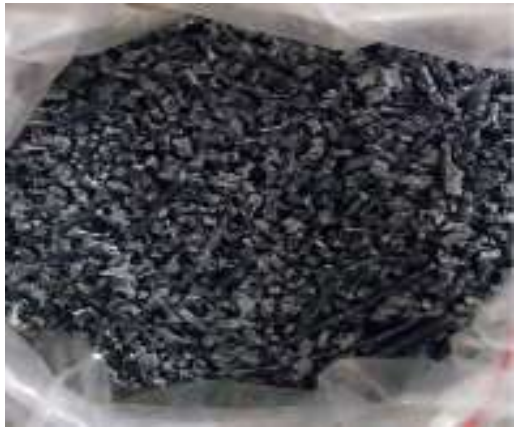

Fig 6: Pelletised e-waste polymer blend

Samples to conduct Tensile and Flexural test is moulded according to ASTM D638M standard using and Pneumatic Injector by injecting the pellets which is dried earlier fig 7 and 8 below shows injection process and tensile, flexural samples of different composition.

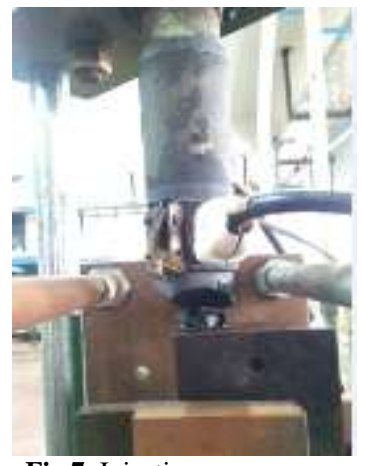

Fig 7: Injection process

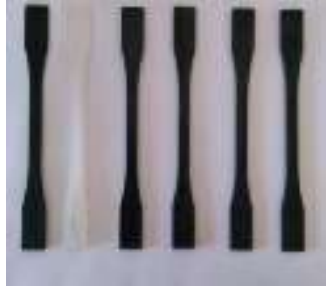

(a)

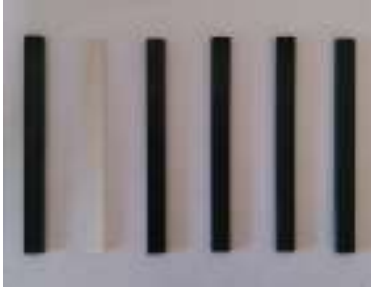

(b)
Fig 8: (a) Tensile testing samples and (b) Flexural testing samples

\section{Result and Discussion}

Tensile strength of the polymer composite were determined by testing the tensile samples in a fully automated Instron Universal testing machine with load cell of 1 Ton capacity. The test specimen and experiment are in accordance with ASTMD638M. The obtained results were tabulated below, it was found that the tensile strength of the e-waste polymer was reduced as addition of the pure polypropylene in the composition of the blend. The decremental in the value of tensile strength was found up to 50/50 composition and thereby gradual increase was found. Results obtained in mechanical testing is tabulated in the Table 1 .

Table I: Mechanical Properties of Abs/Pp E-Waste Polymer Blend

\begin{tabular}{|c|c|c|c|c|c|c|}
\hline \multicolumn{2}{|c|}{ Composition } & \multirow{2}{*}{$\begin{array}{l}\text { Tensile } \\
\text { strength } \\
\text { at peak } \\
\text { MPa } \\
\text { (avg) }\end{array}$} & \multirow{2}{*}{$\begin{array}{l}\% \\
\text { Elong- } \\
\text {-ation } \\
\text { at } \\
\text { break }\end{array}$} & \multirow{2}{*}{$\begin{array}{l}\text { Ultimate } \\
\text { modulus } \\
\text { (Mpa) }\end{array}$} & \multirow{2}{*}{$\begin{array}{l}\% \\
\text { Deflection } \\
\text { at peak } \\
\text { load }\end{array}$} & \multirow{2}{*}{$\begin{array}{l}\text { Impact } \\
\text { strength } \\
\text { (J) }\end{array}$} \\
\hline WE & $\mathrm{PP}$ & & & & & \\
\hline 100 & - & 31.93 & 10.48 & 565.36 & 16.2 & 0.88 \\
\hline 90 & 10 & 29.73 & 10.08 & 454.02 & 15.78 & 0.85 \\
\hline 80 & 20 & 29.54 & 10.02 & 451.86 & 15.45 & 0.825 \\
\hline 70 & 30 & 25.32 & 9.41 & 401.05 & 15.28 & 0.675 \\
\hline 60 & 40 & 25.2 & 9.28 & 400.05 & 14.99 & 0.65 \\
\hline 50 & 50 & 21.37 & 9.68 & 292.8 & 15.12 & 0.6 \\
\hline 40 & 60 & 21.55 & 10.03 & 295.12 & 16.34 & 0.68 \\
\hline 30 & 70 & 22.8 & 10.19 & 311.76 & 18.79 & 0.83 \\
\hline 20 & 80 & 24.02 & 17.34 & 272.78 & 19.54 & 1.16 \\
\hline 10 & 90 & 26.50 & 20.47 & 272.12 & 24.08 & 1.93 \\
\hline- & 100 & 30.14 & 25.82 & 269.01 & 30 & 3.3 \\
\hline
\end{tabular}

Flexural test is carried out in UTM with load cell capacity of 50 $\mathrm{kg}$. The test samples and experimentation are done in accordance with ASTM D790. It can be observed that percentage deflection at peak load or break has decreased at intial stage and incremental values obtained after 40/60 composition as the percentage of pure $\mathrm{PP}$ in the compositeis is majority.

Izod impact test is performed rectangular unnotched sample with specification of the specimen as $62.5 \mathrm{~mm} \times 12 \mathrm{~mm} \times 3 \mathrm{~mm}$. Impact strengths values obtained is in incremental order as the composition value reaches 30/70 the impact value increases than that of waste electronic plastics.

Betterment in the results are observed when the majority of composition is pure polypropylene. which can be seen in the fig 9 and fig 10 . Hence it is evident that recycling of the e-waste plastic with the combination of the pure polymer needs an optimization value so there by using e-waste with optimised quantity can increase the mechanical property of the recycled material.

WEEE plastics will have lesser strength after recycling since it loses its polymer chain during set of thermal cycles such as Extrusion process and Injection process. Which might be the reason for degradation and reduction in the values of mechanical properties .

As the major aim of the work to reuse the plastics of WEEE specifically computer outer panels and keyboard panel plastics better values are needed to provide thebetter quality of the products. In this work results of the composition starting from $40 / 60$ seen the increasing in the properties of the composite. Thus limiting the amount of the e-waste to $40 \%$ and varying the amount of pure polymer content with the addition of a nucleating agents or addition of tertiary polymer in the blend might be the future work line.

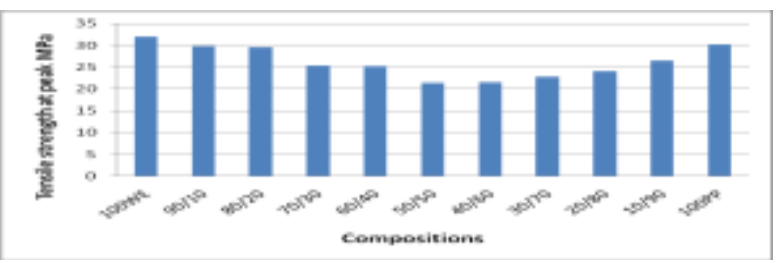

Fig 9: Tensile strength of e-waste polymer blend 


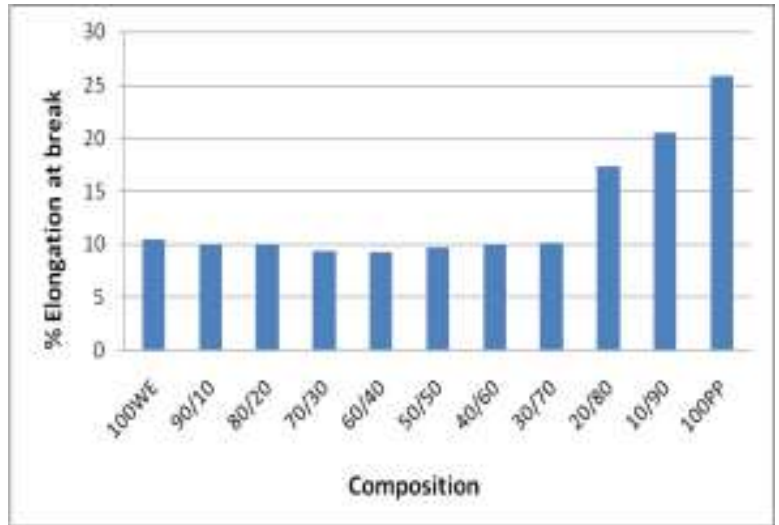

Fig 10: Percentage elongation of the the e-waste polymer blend

\section{Conclusion}

Recycling of plastics in the right manner without effecting the environmental conditions and reusing is necessary nowadays thus an effort has been made to study the mechanical properties of the e-waste polymer blend. It can be concluded as follows,

1. Tensile strength of the e-waste polymer blend having an detrimental order even though addition of the pure polymer PP this might be due to the polymer degradation since ewaste plastics is the combination of two or more polymer (ABS as majority content) and have good strength before recycling and after undergoing set of thermal cycle polymer chain may break and cross link of polymer might be difficult this might lead to improper blending with the pure one.

2. Flexural properties and impact energy of the polymer blend seen a gradual increment with less deviation when compared to results obtained for $100 \%$ WEEE values as the percentage of PP in the composition of e-waste composite is increased.

3. Limiting the volume of the e-waste plastics in the composition to $40 \%$ and varying other content in blends may lead to get comparative results.

\section{Acknowledgment}

I express my sincere thanks to Dr. Siddaramaiah, Head of the Department of Polymer science and technology, SJCE Mysore for providing me the necessary facilities in the department. Also my sincere thanks to Prof. Pradeepa K G of Department of Polymer science and technology, SJCE Mysore greatly indebted to her for guiding me from time to time during the progress of my work.

\section{References}

[1] Pankaj Pathak, Rajiv Ranjan, Srivastava and Ojasvic, "Assessment of legislation and practices for the sustainable management of waste electrical and electronic equipment in India", Renewable and Sustainable Energy Reviews, 78, 2017, pp 220-232

[2] Mahdi Ikhlayel, "Environmental impacts and benefits of state-ofthe-art technologies for E-waste management", Waste Management, 47, 2017. 